\title{
RETRATO DA CIÊNCIA AMAZÔNICA: BOLETINS DO MUSEU PARAENSE EMÍLIO GOELDI
}

\author{
Portrait of Amazon Science: \\ the newsletters of the Paraense Museum Emílio Goeldi \\ Retrato de la Ciencia Amazonica: \\ Boletines del Museo Paraense Emílio Goeldi
}

\begin{abstract}
Elaynia Cristina Vicente Ono Mestra em Ciência da Comunicação pelo PPGCOM/UFPA, integrante do Grupo de Pesquisa em Propaganda e Publicidade - GRUPPU (UFPA/CNPq). elayniaono@hotmail.com
\end{abstract}

Guaciara Barbosa de Freitas Doutora em Ciências da Comunicação pela Universidade do Vale do Rio dos Sinos. Jornalista integrante da Assessoria de Comunicação da Universidade do Estado do Pará. guacifreitas@yahoo.com.br

\section{Resumo}

Em uma articulação entre edição, cultura e história, este artigo analisa como a fase de criação do Boletim do Museu Paraense Emílio Goeldi contribuiu com a consolidação do periódico científico mais antigo em circulação no Brasil. Realizamos pesquisa documental e bibliográfica, com abordagem quantitativa/qualitativa e análise exploratória de conteúdo. Aqui, focalizamos um período da trajetória dos Boletins, de 1894 a 1914, e adotamos a produção gráfica, a edição e a circulação como alguns dos marcadores desta sistematização. Concluímos que, apesar de os conhecimentos necessários à editoração na época decorrerem da xilografia, zincografia e "correlativas artes gráficas", e da carência de recursos humanos e materiais, os aspectos visuais foram reconhecidos como fundamentais ao fortalecimento de um circuito comunicativo na Amazônia e a partir dela.

Palavras-chave: Boletins do Museu Paraense Emílio Goeldi. Edição. Comunicação científica.

\begin{abstract}
In an linking between edition, culture and history, this article analyzes how the development stage of the Bulletins of the Museu Paraense Emílio Goeldi, contributed to the consolidation of the oldest scientific journal in circulation in Brazil. We carry out documentary and bibliographic research, with a quantitative / qualitative approach and exploratory content analysis. Here we focus on a phase of the Bulletin's trajectory, from 1894 to 1914 and we adopt graphic production, periodicity and circulation as some of the markers of this systematization. We conclude that despite the knowledge necessary for publishing at the time, stem from xylography, zincography and "correlative graphic arts" and the lack of human and material resources, the visual aspects were recognized as fundamental to the strengthening of a communicative circuit in the Amazon and from it.
\end{abstract}


Key words: Bulletins from the Museu Paraense Emílio Goeldi. Edition. Scientific communication.

\section{Resumen}

En una articulación entre edición, cultura e historia, este artículo analiza cómo la fase de creación de los Boletines del Museo Paraense, contribuyó a la consolidación de la revista científica más antigua en circulación en Brasil. Realizamos investigaciones documentales y bibliográficas, con un enfoque cuantitativo / cualitativo y análisis de contenido exploratorio. Aquí nos centramos en una fase de la trayectoria del Boletín, de 1894 a 1914, y adoptamos la producción gráfica, la edición y la circulación como algunos de los marcadores de esta sistematización. Llegamos a la conclusión de que, a pesar del conocimiento necesario para la publicación en ese momento, provienen de la xilografía, la zincografía y las "artes gráficas correlativas" y la falta de recursos humanos y materiales, los aspectos visuales fueron reconocidos como fundamentales para el fortalecimiento de un circuito comunicativo en la Amazonía y de él.

Palabras clave: Boletines del Museu Paraense Emílio Goeldi. Edición. Comunicación científica.

\section{ONDE EMERGE O OBJETO}

Os séculos XVIII e XIX foram períodos de grande interesse para a investigação científica no Brasil, especialmente na região amazônica. Alguns exemplos disso foram as notórias expedições lideradas por Alexandre Rodrigues Ferreira - um naturalista brasileiro, formado na Universidade de Coimbra, que explorou a região entre os anos de 1785 e 1792 - e as viagens realizadas pelos naturalistas bávaros Jonhann von Spix e Carls von Martius expedição que partiu de São Paulo, no final de 1817, passando por Minas Gerais, pelas regiões do Nordeste brasileiro, navegando pelo rio Amazonas, até alcançar a cidade de Belém.

Com a descoberta da exuberância do mundo natural da região e o constante fluxo de naturalistas viajantes, que exploravam as riquezas locais, foi reforçada a importância de se criar um Museu de História Natural e de artefatos indígenas que pudesse estudar, preservar e expor elementos da natureza amazônica no próprio país, que há tempos já vinham encantando o público dos museus pelo mundo (LISBOA, 2010; SANJAD, 2009, 2010).

Foi seguindo o modelo dos museus até então implantados no país que Emílio Augusto Goeldi, a convite do governador do estado do Pará, Lauro Sodré, assumiu o compromisso de revitalizar o Museu Paraense, que se tornaria um polo de estudos baseados na cultura de intercâmbio de experiências e também de produção de saberes amazônicos, promovendo, assim, o desenvolvimento científico na região. Na carta-circular publicada no volume 1 , número 1, do Boletim do Museu Paraense de História Natural e Etnografia, Goeldi explicitava a natureza da instituição: 
[...] instituto para a história natural da Amazônia, um estabelecimento que se propõe a observar, colecionar, determinar e tornar conhecidos os objetos da natureza indígena [...] prestará igualmente toda a atenção ao ramo etnográfico, visto que se trata de uma região altamente interessante neste sentido. A zoologia e a botânica sobretudo - ciências, minhas prediletas prometem fornecer um campo de trabalho opulento (GOELDI, 1894a, p. 9).

O zoólogo Emílio Goeldi desembarcou no Brasil em 1884, atraído pelas possibilidades de desbravar, nestas terras, o mundo natural. Inicialmente, assumiu o cargo de subdiretor da Seção de Zoologia do Museu Nacional do Rio de Janeiro, onde permaneceu por seis anos, dedicando-se aos estudos nas áreas de biologia, zoologia e à zoologia aplicada na agricultura. Com a Proclamação da República, o cenário brasileiro passou por profundas transformações nos campos sociopolítico, econômico e cultural, as quais se refletiram também nas instituições, com o desligamento de vários cientistas de suas instituições de pesquisa, que haviam sido contratados pela Corte. As mudanças às quais o Museu Nacional foi submetido, juntamente com outras questões conflitantes, transpuseram Goeldi para outra realidade, desvinculada da instituição. Seu trabalho e a colaboração de seus estudos para o país chegaram, contudo, ao conhecimento do governador do estado do Pará, Lauro Sodré, que o convidou a assumir o cargo de diretor do Museu Paraense (SANJAD, 2009, p. 31-41).

Para Sodré, "cultivar a ciência e investir na educação do povo eram exigências do progresso, razões da República e deveres de um dirigente ilustrado" (apud SANJAD, 2010, p. 165). Assim, Goeldi encontrou no panorama político e econômico o incentivo para o desenvolvimento científico na região, elencando, entre as suas principais metas, configurar uma tradição de produção e de difusão da ciência na Amazônia, o que elevou o primeiro centro de ensino superior no Pará como polo mais importante de movimento científico nacional sobre as questões amazônicas. Este fato atrairia a atenção de pesquisadores estrangeiros, projetando o Museu a patamares internacionais. O novo dirigente do Museu importou o quadro de pesquisadores que atuariam na instituição e, entre os requisitos necessários para a ocupação desses cargos, preponderava a formação em ciências naturais, a publicação de trabalhos originais e a "probidade científica".

Em consultas aos jornais da época, notamos o entusiasmo com o qual eram anunciadas as notícias sobre o Museu Paraense, de modo que os assuntos referentes à instituição eram amplamente divulgados: Vae ser definitivamente instalada na chácara que pertence ao sr. Coronel Bento José da Silva, á estrada da Independencia, o Muzeu Paraense. A chácara já foi entregue ao governo por compra, para aquelle fim. Além de um edifício com vastos compartimentos, solidamente construídos, dispõe aquella propriedade de extenso terreno que confina com a estrada da Constituição. Foi uma feliz 
aquisição. O Muzeu, além de uma exposição permanente de objetos representando todos os ramos da natureza, terá duas dependências especiaes: um jardim zoológico contendo exemplares de todos os animais vivos da Amazonia; um jardim botânico, scientificamente classificado (A PROVÍNCIA DO PARÁ, 1895, p. 2).

A publicação dos primeiros exemplares do periódico científico do Museu Paraense era noticiada com este mesmo ânimo. Algumas pesquisas eram veiculadas na forma de um pequeno resumo, reproduzindo o que já havia sido comunicado pelo Boletim.

Essa presença constante de matérias tanto sobre o Parque Zoobotânico, quanto sobre as pesquisas e o avanço das ciências na instituição, em editoriais dos jornais da época, comprovava o sucesso do empenho que Goeldi empreendeu na criação de um Museu de História Natural e Etnografia. Vulgarizar ${ }^{1}$ a ciência era o objetivo institucional maior e, para Goeldi, levar esses assuntos ao público em geral, não apenas aos seus pares, era de suma importância para educar a população. Os periódicos eram distribuídos em profusão pelo estado, sendo contemplados principalmente professores e estabelecimentos de ensino público; outra cota era reservada aos círculos oficiais e civis da sociedade paraense e a quem mais pudesse apresentar interesse pelo assunto (GOELDI, 1896b, p. 232).

Goeldi revelou-se não apenas como produtor, como também como grande difusor da ciência amazônica. Na condução de seus atos, investiu na construção de uma relação muito bem articulada entre os jornalistas, os cientistas, os professores e os comentaristas de várias formações, com o objetivo de educar o olhar e o pensamento da população, valorizando campos sociais que avançavam de maneira extraordinária no século XIX, o da ciência e o da técnica.

\section{A EDIÇÃO DE UM PERIÓdICO CIENTÍFICO PARA OS PARES E PARA O POVO}

O Boletim do Museu Paraense de História Natural e Ethnographia é um dos primeiros documentos de difusão e de registro do fomento científico no Norte do país. Atualmente, é um dos mais antigos ainda em circulação no Brasil, funcionando desde 1894. Este periódico científico surge da intenção de configurar, na região, uma tradição da produção científica voltada ao intercâmbio de experiências entre os pesquisadores da Amazônia e do resto do mundo, gerando interesse quanto ao subsídio a estudos feitos na região e para a região,

\footnotetext{
${ }^{1}$ Neste caso, o termo "vulgarizar" está presente no texto com a mesma conotação utilizada, à época, por Goeldi, tendo o sentido de "popularizar".
} 
expectativa que Goeldi deixa claro no prefácio do primeiro número: "Publicaremos trabalhos originais, realizados aqui por nós e por colegas, que estão em contato conosco, [...] fiscalizando o que se vai fazer fora, longe daqui, em outras partes do mundo, por naturalistas com quem ainda não travamos relações" (GOELDI, 1894b, p. 11).

Para Goeldi, a intenção da publicação era a de reunir material a fim de promover o levantamento do conhecimento científico produzido sobre a Amazônia e buscar "preencher as lacunas" do que já se sabia, bem como do que ainda estava por ser investigado, para "chamar para elas [as lacunas] a atenção pública" (GOELDI, 1894b, p. 11).

Ainda no prefácio da primeira edição, Goeldi explica que o Boletim não teria compromisso com a periodicidade, deixando o futuro encarregado desta questão. O tempo era quem determinaria os intervalos das publicações, que sairiam de acordo com as proporções do material existente. Porém, na publicação de 1904, foi possível verificar a declaração de Emílio Goeldi expondo a sua intenção real, que era a de produzir quatro fascículos, os quais corresponderiam a um tomo, dentro do intervalo de aproximadamente 18 meses, fato somente revelado posteriormente, para não causar expectativas que poderiam ser frustradas, o que, de fato, aconteceu. Goeldi alegava que as dificuldades em manter a periodicidade estavam associadas ao obstáculo de dispor, em Belém, de "pessoal habilitado em composição", o que prejudicava a execução tipográfica de grandes volumes e com tempo determinado.

O tomo I do Boletim do Museu Paraense de História Natural e Ethnographia foi produzido no período de 1894 a 1896 (Figura 1), ficando a redação a cargo do corpo científico da instituição e do diretor. Este volume continha os fascículos 1 a 4, lançados separadamente durante este período. Observamos que o primeiro volume do Boletim está datado como sendo uma publicação de 1896, ano que se refere à conclusão dele, que, no momento da encadernação, priorizava a data do último fascículo. Mas, o primeiro fascículo, que estabelece de fato o surgimento do Boletim, foi produzido em setembro de 1894. 
Figura 1 - Capa da primeira edição do Boletim do Museu Paraense de História Natural e Ethnographia.

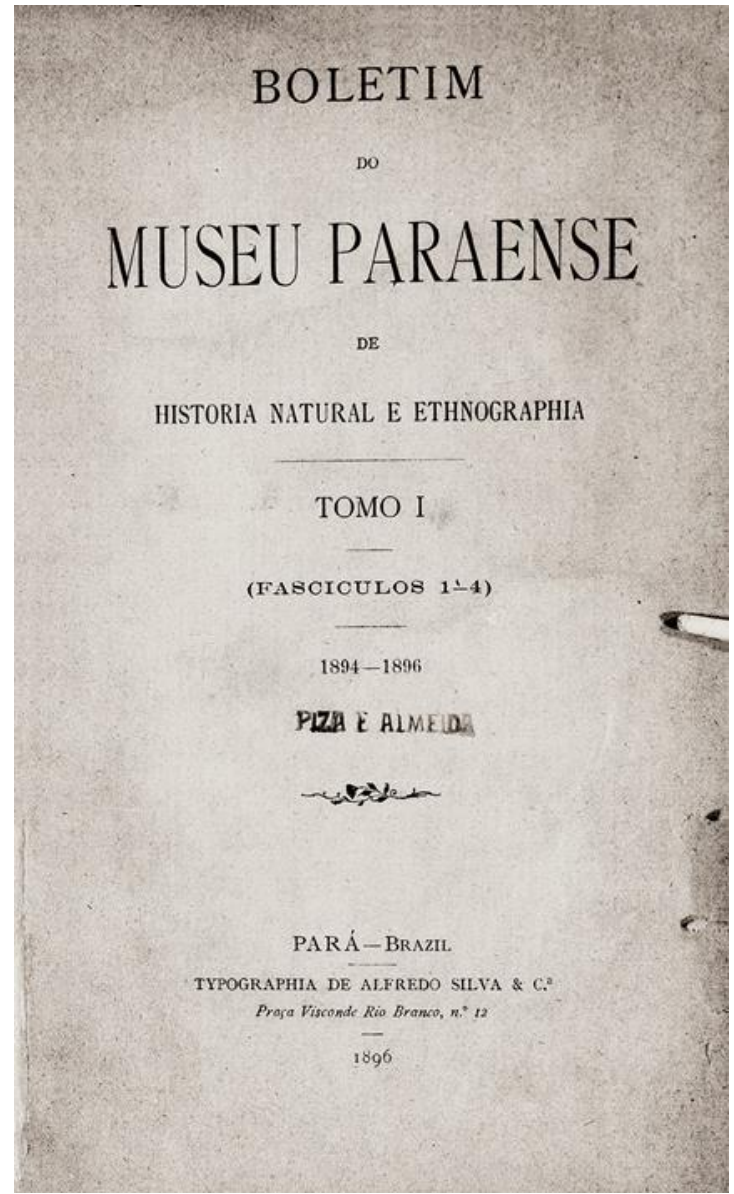

Fonte: Boletim do Museu Paraense de História Natural e Ethnographia (1894-1896).

Esses primeiros fascículos foram compostos sob a tipografia de Alfredo Silva \& $\mathrm{Ca}$, localizada na Praça Visconde Rio Branco, no 12, estado do Pará, Brasil. Uma tiragem de mil exemplares seria distribuída gratuitamente, e ao "arbítrio do diretor", sendo uma parte dela reservada às permutas, estabelecendo-se, desta forma, um vínculo com outras instituições científicas, tanto nacionais quanto internacionais. Uma das exigências de Goeldi foi que, mesmo sendo o Boletim uma publicação de alcance internacional, deveria permanecer com sua "roupagem nacional", e todos os seus artigos deveriam ser impressos em língua portuguesa, fortalecendo, dessa forma, uma identidade local (Figura 2). 
Figura 2 - Trecho do prefácio da primeira edição do Boletim do Museu Paraense de História Natural e Ethnographia ressaltando a importância da publicação em língua portuguesa.

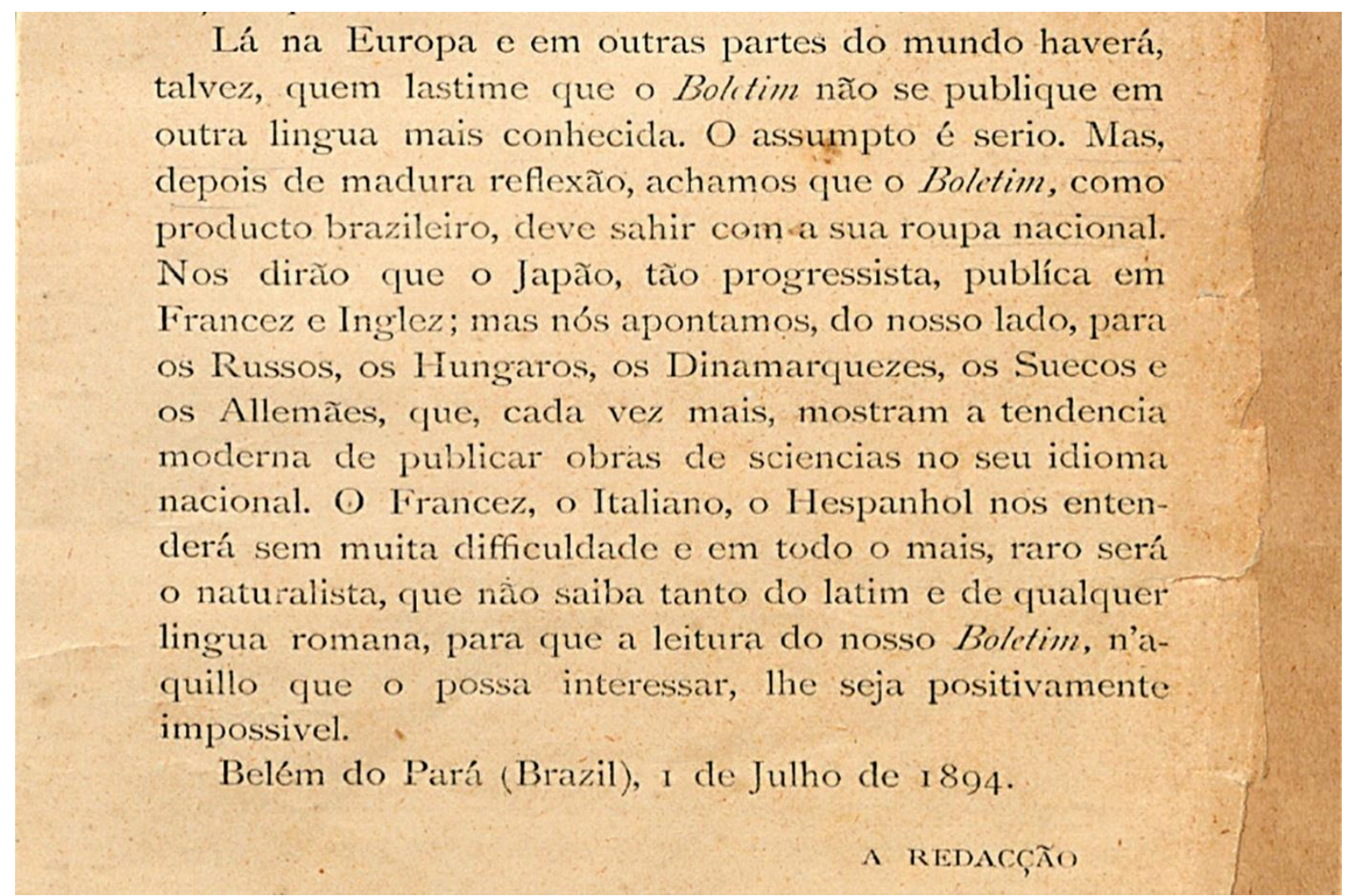

Fonte: Boletim do Museu Paraense de História Natural e Ethnographia (1894, p. 3).

Percebemos na expressão do modo de ver e de fazer, impresso por Emílio Goeldi no direcionamento editorial dado ao periódico científico que organizava, marcas da contemporaneidade de acordo com a acepção concebida por Agamben (2009), ao evocar o sentido de intempestividade em Nieztsche, evidenciando como poderia aquele contexto intempestivo, aparentemente inoportuno e de certa forma atritando-se a práticas comuns a seu próprio tempo, ser tomado como contemporâneo:

A contemporaneidade, portanto, é uma singular relação com o próprio tempo, que adere a este e, ao mesmo tempo, dele toma distâncias; mais precisamente, essa é a relação com o tempo que a este adere através de uma dissociação e um anacronismo. Aqueles que coincidem muito plenamente com a época, que em todos os aspectos a esta aderem perfeitamente, não são contemporâneos porque, exatamente por isso, não conseguem vê-la, não podem manter fixo o olhar sobre ela (AGAMBEN, 2009, p. 59).

Sob a perspectiva dada por Giorgio Agamben, a leitura daqueles gestos decisivos, que marcam a criação do periódico científico, permite-nos captar alguns dos movimentos de ruptura naquele presente, nele inserindo vestígios do "arcaico", como a adoção da língua de origem do periódico, ainda que isso não parecesse adequado aos propósitos de 
internacionalização da publicação. Assim, ao editar o Boletim, Goeldi e sua equipe de cientistas lançam um novo olhar para seu tempo, como também para o passado e, por que não dizer, para o futuro.

Ainda que a adoção da língua portuguesa tenha sido assumida como uma estratégia de divulgação, aliada ao intento de valorizar a origem da publicação, o periódico incluía páginas específicas publicadas em língua inglesa, francesa e alemã, que se referiam a convites direcionados a "Academias, Sociedades Científicas, Museus, Institutos, Universidades e Escolas de Tecnologia" e também a "Naturalistas e Especialistas" (BOLETIM DO MUSEU PARAENSE DE HISTÓRIA NATURAL E ETHNOGRAPHIA, 1894, p. 8, tradução nossa), visando à permuta de publicações de cunho científico. Esta estratégia provou ter grande eficiência para a composição da biblioteca do Museu, visto que o relatório de 1895, ano posterior à publicação do primeiro Boletim, registrava que já havia na instituição um acervo de aproximadamente 800 volumes de diversas obras literárias, doadas por instituições parceiras (GOELDI, 1895; BOLETIM DO MUSEU PARAENSE DE HISTÓRIA NATURAL E ETHNOGRAPHIA, 1897, p. 15).

Nos seus primeiros momentos, o Boletim foi muito mais do que um periódico direcionado à comunidade científica, com atuação que consistiu mais em servir de interlocutor a todos que tivessem interesse em conhecer os assuntos amazônicos. Por meio da adoção de um discurso atrativo e íntimo, apresentava preocupação no uso de uma linguagem acessível a todos os leitores, fossem eles leigos ou não. Todos eram igualmente tratados como "amigos da natureza" amazônica, incentivados à curiosidade em acessar os conhecimentos ali difundidos. Nesse sentido, embora alinhado ao paradigma moderno da ciência, o Boletim também incorporou marcas de um outro movimento, de certa forma vanguardista, pois, ao mesmo tempo em que buscou legitimar o fazer e o campo científico na região, não o colocou em uma dimensão apartada da sociedade, restrita aos pares. Tal estratégia buscou fortalecer essa legitimação com ações que ampliavam as possibilidades de aproximação com a sociedade.

$\mathrm{Na}$ redação da obra aqui apresentada ao público deixei-me guiar principalmente pelas considerações seguintes: em primeiro logar esperava eu servir os interesses da sciencia, para a qual a enumeração exacta de colecções tão extensas como as nossas deve ser de valor sob o ponto de vista systematico e zoogeographico. Mas também eu queria dar aos numerosos amigos da natureza um guia seguro que permitisse orientarem-se na estupenda diversidade de formas da avifauna do seu paiz, animandoos assim a colaborar na sua exploração. Para conseguir este fim dei todas as vezes que foi possivel os nomes triviaes ao lado scientifico e elaborei descripções 
detalhadas ainda que curtas de cada um dos pássaros mencionados. Para facilitar a orientação geral organizei as chaves de determinação que precedem as enumerações, das ordens, famílias, gêneros, espécies e comspecies; visei antes de tudo a utilidade pratica usando de caracteres faceis a reconhecer e ilustrando-os quando possível por meio de figuras. Quanto á nomenclatura technica, especialmente diffícil n'uma língua, onde a terminologia ornithologica quase não existia até há bem pouco tempo, empreguei o mais possivel as expressões usadas pelo Dr. Goeldi nos seus trabalhos relativos á avifauna brasileira. Estou bem consciente dos muitos defeitos d'este trabalho. Além da própria imperfeição, alguns d'elles já provem da dificuldade de conciliar as exigencias da sciencia pura com as necessidades do leitor, amador da natureza mas sem instrucção estrictamente scientifica. Também deve-se tomar em consideração a circumstancia que o autor, sendo strangeiro, não sabe a língua portugeza com a segurança desejavel para tal assumpto. Se terei conseguido, a pesar d'isto, estimular um ou outro dos leitores a empreender investigações próprias e a colaborar no campo tão rico e tão interessante da ornithologia sulamericana, não julgarei perdido o tempo dedicado a este livro (SNETHLAGE, 1914, p. 1-2).

O trecho do editorial escrito por Emilie Snethlage - doutora em Ciências Naturais pela Universidade de Freiburg (Alemanha), única mulher integrante da equipe de pesquisadores do Museu, diretora interina da instituição em 1914 -, na edição editada durante sua gestão, demonstra exatamente o esforço materializado no Boletim de realizar, a um só tempo, comunicação científica e divulgação da ciência, em sintonia com o que hoje se denomina como cultura científica (VOGT, 2006, p. 24-25), segundo a ideia de que o desenvolvimento científico é um processo cultural, seja no âmbito de sua produção, da sua difusão entre pares ou na dinâmica social do ensino e da educação, configurando, portanto, um processo de mediação social importante "para o estabelecimento das relações críticas necessárias entre os cidadãos e os valores culturais, de seu tempo e de sua história".

A análise dos Boletins enquanto instrumentos de um ideal civilizatório (os quais também serviram como ferramenta de educação e de popularização do conhecimento científico) demonstra o engajamento deles nas relações econômicas e políticas em meio ao tecido social local, bem como leva-nos a observar a validação e o reconhecimento destes veículos, processo efetuado por meio das mídias tradicionais locais e da aceitação da sociedade. Os periódicos configuraram-se, assim, como produtos e, ao mesmo tempo, objetos propulsores na tentativa de consolidação da ciência na região, pois atuaram àquela época - e ainda nos tempos de hoje - também como condicionantes do processo de institucionalização da comunicação científica local e a partir dele para o mundo. 


\section{MARCAS EDITORIAIS NO CONTEÚDO E NA FEIÇÃO EXTERNA}

Os primeiros assuntos descritos no periódico estavam relacionados aos relatórios administrativos e de viagens, a memorandos, a alguns estudos taxonômicos do próprio Emílio Goeldi, a descrições de espécimes de animais e de plantas, em todas as suas classificações, além de publicação de estampas de representações de artefatos indígenas e arqueológicos e de espécimes da flora e da fauna amazônicas.

O Boletim também contou com a colaboração de pesquisadores estrangeiros, a maioria deles composta por homens. Conforme dados sistematizados por Benchimol (2015, p. 96-97), $50 \%$ desses autores predominavam na área de Zoologia; enquanto que, na Botânica, a expressividade foi de 31\%; a Geologia contava com 12\% de autores; e a Etnologia, com menor representatividade, apresentava apenas $8 \%$ dos pesquisadores estrangeiros que atuaram no período de 1894 a 1914 no Boletim.

Como nesta fase a publicação não se configurava como elemento presente somente no âmbito do desenvolvimento científico, uma vez que mediava, em alguns momentos, as relações políticas e econômicas da região. Várias das pesquisas publicadas também eram de interesse da saúde pública, como a classificação e a descrição de espécimes de mosquitos da região, especialmente os que possibilitaram uma agenda científica voltada ao combate e ao controle de doenças, como a filariose, a malária e, especialmente, a febre amarela, que epidemicamente afligia a população da época.

Vale ressaltar que o surto de febre amarela prejudicou demasiadamente os setores econômico e político, fazendo com que Goeldi recebesse total apoio do governo em suas pesquisas sobre os mosquitos do Pará, as quais posteriormente incentivariam ações por parte dos responsáveis pela saúde pública. Introduziram-se novos hábitos na prática cotidiana, como a indicação do uso de mosquiteiros e de telas protetoras nas residências e o combate aos mosquitos que eram vetores de doenças. Conforme as palavras de Goeldi (1904, p. 197):

Entre as conclusões práticas a tirar do ponto de vista sanitário, creio poder apontar principalmente para as seguintes: as nossas experiências demostram nitidamente que, realizada a viagem, convém dissolver o convívio dos passageiros o quanto antes [...] por frequentes e radicais desinfecções com reativos eficazes (dióxido de enxofre etc.) [...]. Vapores, navegando, com especialidade e regularmente entre portos sitos, na zona tropical e pretendendo obedecer nos arranjos internos ás indicações higiênicas modernas contra os perigos acarretados pelos mosquitos transmissores de moléstia, deveriam ter como dormitórios para a tripulação e os passageiros, acomodações providas com telas protetoras. 
Outras pesquisas publicadas no Boletim também fizeram parte de agendas específicas do governo, a exemplo da veiculação dos estudos da expedição realizada por Goeldi na região do contestado franco-brasileiro:

Durante mez e meio percorremos a zona entre Amapá e o Counany, extendendo as nossas excursões ao norte até o rio Cassiporé e para o interior, subindo os rios, até onde as circumstancias momentâneas o permittiam. Havendo, de nossa parte, o projecto de tornar os resultados scientificos de nossas viagens objeto de uma publicação maior, illustrada com as numerosas vistas photographicas, que levantamos, não entro aqui em pormenores e pronuncio apenas ainda a esperança, que venham para o Estado do Pará, o Brasil e a humanidade inteira douradoras vantagens d'esta nossa notável expedição, que tão amargos sacrifícios custou ao pessoal do Museu Paraense (GOELDI, 1896b, p. 23).

O material produzido pelas expedições no local da disputa rendeu um mapeamento cartográfico e fotográfico, além de estudos da fauna, da flora e da arqueologia, o qual serviu de fonte de informações estratégicas para a condução das negociações territoriais entre Brasil e França, caracterizando-se como dados de suma importância para a definição dos limites do território brasileiro. Goeldi, que também atuou como interlocutor entre os dois governos, posteriormente obteve relevante reconhecimento por parte do governo brasileiro (SANJAD, 2006).

O Boletim desse período inaugural também trouxe estudos nas áreas de meteorologia, apresentando inovações tecnológicas, como o sistema Richard-Paris, que contribuiu para o conhecimento do clima do Pará, anunciando a temperatura média anual da cidade de Belém, girando em torno de $25,7{ }^{\circ} \mathrm{C}$ (GOELDI, 1904). O material estatístico produzido chamou a atenção do diretor do serviço meteorológico austríaco e redator da Revista Internacional de Meteorologia, professor Dr. Julius Hann, em Vienna, que declarou a importância das pesquisas para o conhecimento exato do clima equatorial.

Essa inovação tecnológica também possibilitou que os jornais noticiassem diariamente a situação meteorológica de Belém, fato importante para aqueles que dependiam das condições do tempo para realizar e planejar seu cotidiano. As observações disponibilizadas pelo Museu eram apresentadas em um quadro descritivo, citando, entre outros elementos, a ocorrência de nuvens, direção e força dos ventos e das chuvas; era possível, a partir disso, verificar, com maior exatidão, a previsão do tempo.

Durante a sua trajetória, os Boletins passaram por diversas mudanças, resultantes do percurso atravessado pela institucionalização da ciência na Amazônia, bem como em razão de suas relações com o contexto político e econômico de cada período. Embora o foco deste 
artigo seja a fase inicial, apresentamos as fases do periódico de forma visual (Figura 3), de maneira a evidenciar o percurso centenário do Boletim. Há destaque para as capas que representam cada fase e uma linha do tempo, feita por meio de distintas cores, com as quais identificamos etapas sistematizadas, acompanhadas pela denominação formal que os periódicos receberam em cada uma delas.

Figura 3 - Linha do tempo dos Boletins.

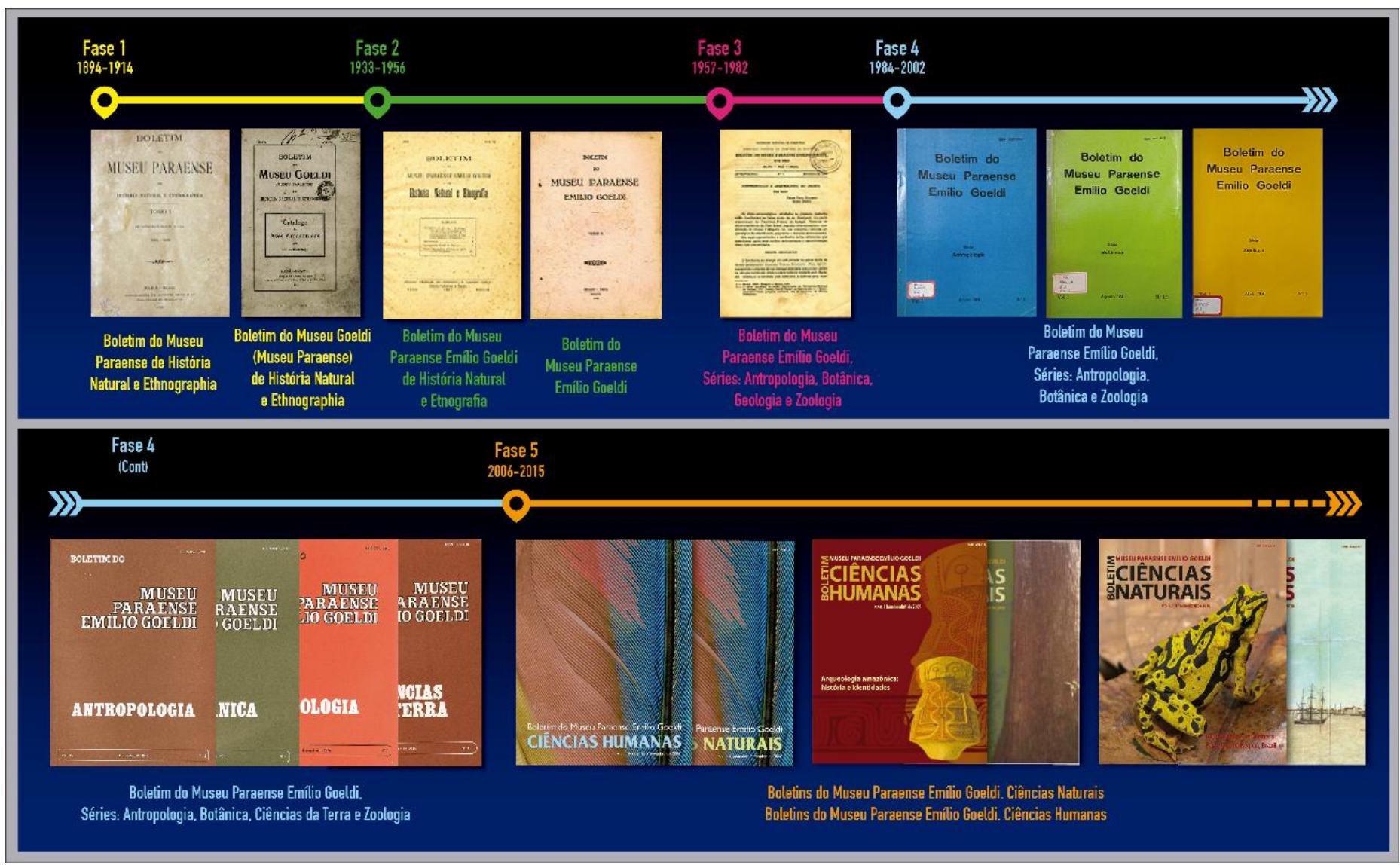

Fonte: Ono (2018, p. 75).

A fase 1, que focalizamos no presente texto, abrange o período de 1894 a1914, no qual houve intensa atividade científica na região amazônica, não apenas desenvolvida por naturalistas viajantes, mas também sendo concebida, promovida e realizada por instituições brasileiras, como o próprio Museu Paraense (posteriormente denominado Museu Paraense Emílio Goeldi), o Museu Paulista e o Instituto Oswaldo Cruz. A fase tem início no primeiro fascículo do periódico (setembro de 1894) e finda com a interrupção do mesmo, causada pela crise financeira percebida pela Amazônia e pelo MPEG no contexto da Primeira Guerra Mundial, seguindo-se longo período de inatividade. 
Esta fase está inserida no que Nonato (2012), bem como Faulhaber \& Toledo (2001) consideram como o período em que a institucionalização da ciência na Amazônia se desenvolveu efetivamente, a partir da grande expansão da economia extrativista do látex, no final do século XIX. Está também no momento situado por Dantes (1988) como característico da introdução da ciência experimental no Brasil. Estes dois episódios ocorrem no intervalo do século XIX até 1920. A esses dois parâmetros, foi adicionada a divisão estabelecida pelo zoólogo e memorialista Osvaldo Cunha (apud SANJAD, 2001), que aponta para uma fase iniciada na reformulação promovida por Goeldi na instituição, e que se estenderia até o final da gestão de Emilie Snethlage (1894-1921).

Ainda que efetivamente delimitada pela publicação do primeiro Boletim, este momento inicial possui seu marco introdutório alguns anos antes, em 1891, quando, superando um período de grandes dificuldades, o Museu é reinstalado no edifício da Escola Prática, saindo do prédio do Liceu Paraense, no qual havia sido acomodado anteriormente. Refletindo um cenário moderno de disciplinarização das áreas científicas, em seus primeiros anos, as publicações tiveram uma concentração maior nas áreas de Botânica e de Zoologia. Neste primeiro período, foram publicados oito volumes, sem compromisso com periodicidade, conforme mencionado pelo próprio Goeldi, no prefácio do primeiro número da revista. A determinação de publicar o periódico constava, inclusive, no regulamento da própria instituição.

Inicialmente, os sumários apresentavam-se divididos em duas seções: uma dedicada a assuntos administrativos, com temas relativos ao próprio Museu, apresentando relatórios, regimentos, detalhamento dos gastos com a manutenção da instituição e com as publicações produzidas, incluindo o Boletim e outras obras realizadas pelo Museu Paraense, e também informações sobre o estado em que a instituição se encontrava; a outra seção era destinada aos assuntos científicos, expondo estudos das áreas de Zoologia, Botânica, Geologia, Arqueologia e Etnografia, descrição de viagens, expedições e excursões realizadas por pesquisadores, assim como biografias e ilustrações, conforme a Figura 4. 
Figura 4 - Índice do primeiro número do Boletim do Museu Paraense de História Natural e Ethnographia.

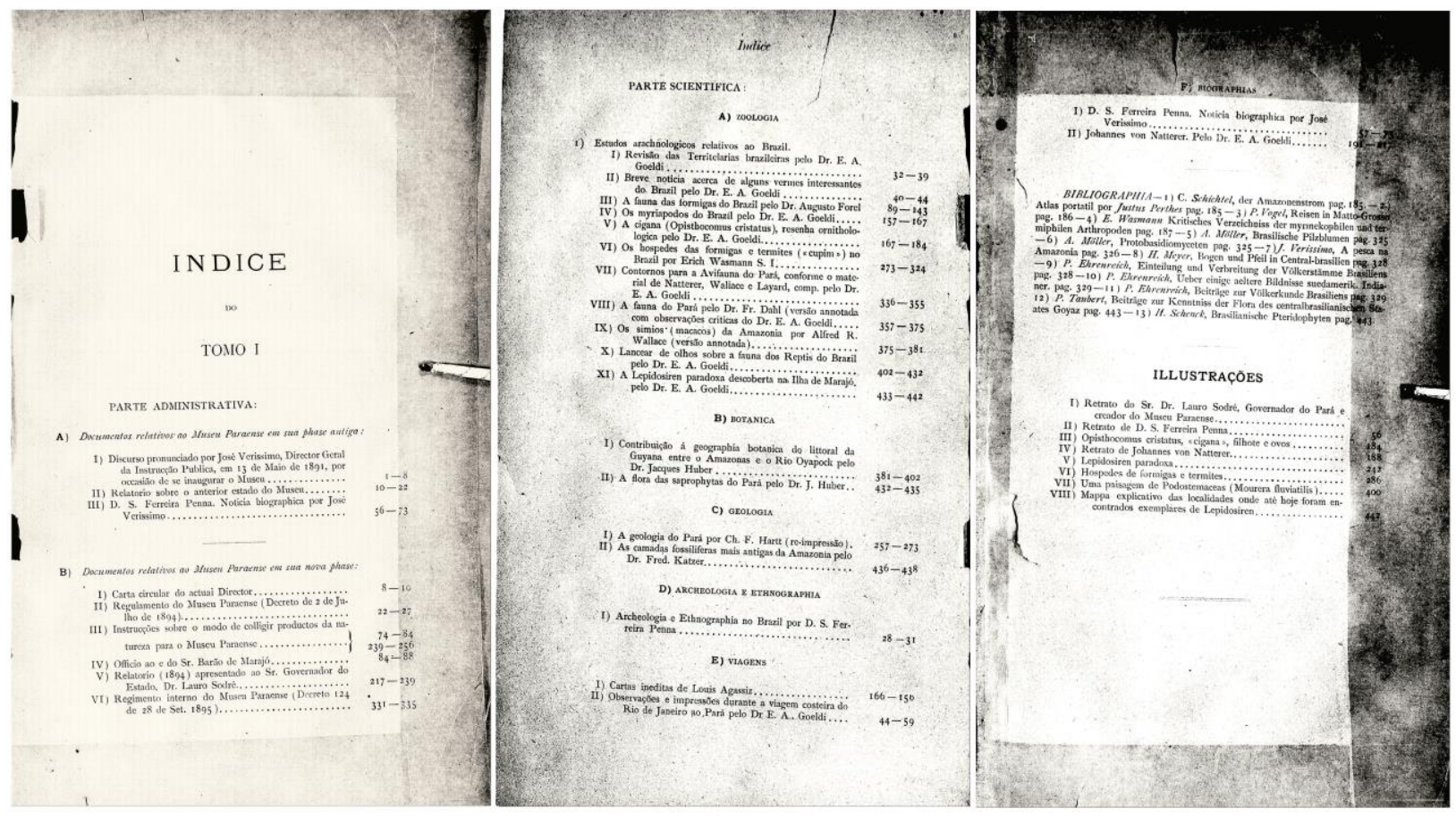

Fonte: Boletim do Museu Paraense de História Natural e Ethnographia (1894).

Em sua totalidade, o Boletim foi planejado como suporte comunicacional estratégico também em sua dimensão visual, possibilitando, por exemplo, a inclusão de fotografias nas primeiras páginas como forma de homenagem, algo que se tornou habitual em números subsequentes. Lauro Sodré (Figura 5) foi o primeiro a ter a sua face revelada; o número seguinte do periódico, publicado em 1895, saudou a figura de Domingos Soares Ferreira Penna, fundador da Sociedade Philomática Paraense; e o posterior, datado de 1896, prestou reverência ao importante naturalista austríaco Johannes von Natterer, reconhecido por ter organizado uma das maiores coleções de objetos etnográficos e de história natural do Brasil no século. 
Figura 5 - Homenagem a Lauro Sodré.

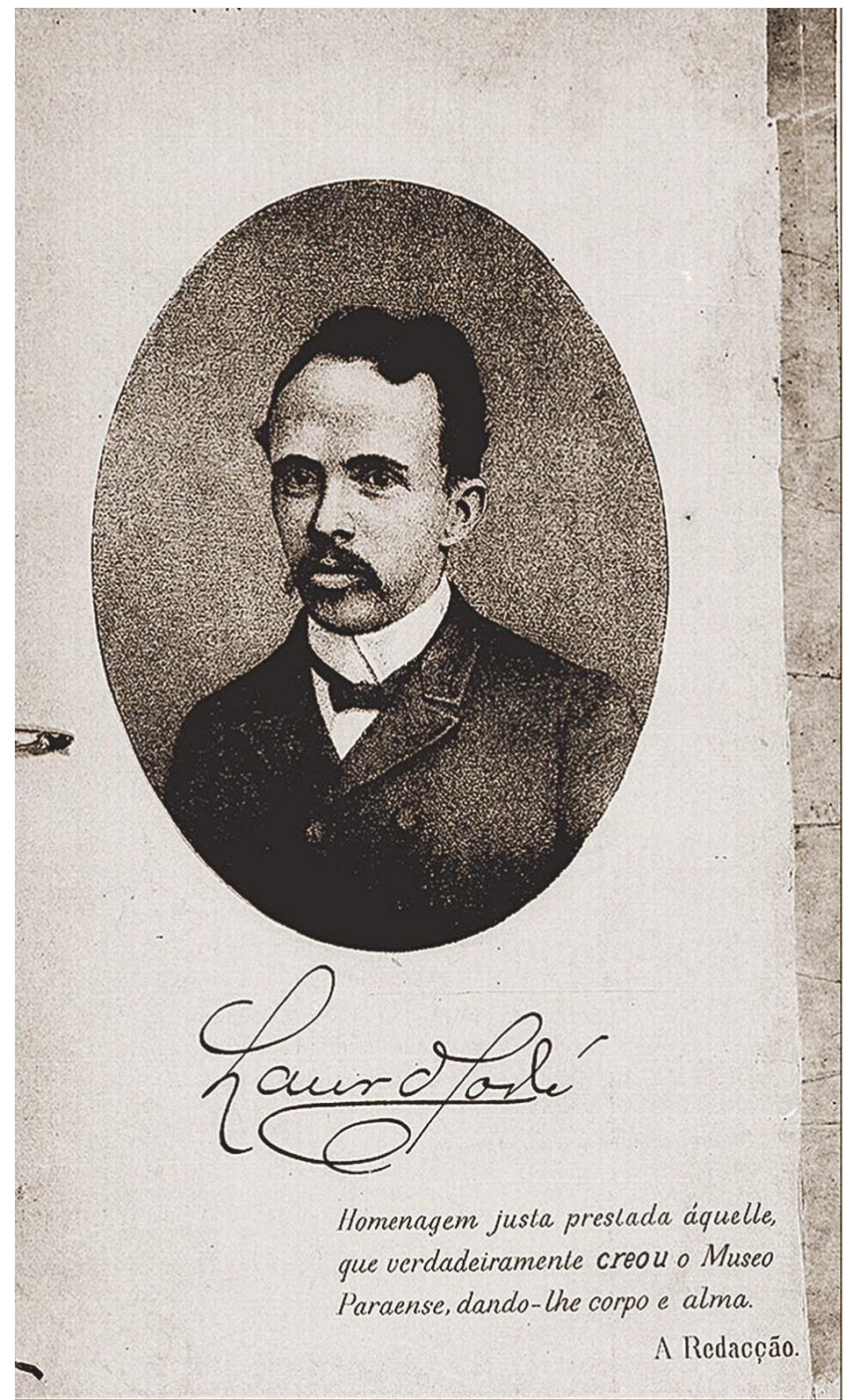

Fonte: Boletim do Museu Paraense de História Natural e Ethnographia (1894, p. 9).

Desse modo, a utilização das fotografias, nas páginas iniciais, servia para projetar certa imponência, por meio da postura altiva dessas personalidades, que eram envolvidas com as atividades científicas e políticas. Este gesto se caracterizava como uma espécie de comprometimento pessoal com a promoção da ciência, que se manifestava de forma mais racional, dura e masculina na época.

Os aspectos gráfico e visual possuíam importância particular na confecção do primeiro Boletim. Neste período de bonança econômica, a revista pôde lançar mão dos recursos visuais que estavam ao seu dispor para criar uma "ideologia científica", associada aos conceitos de modernidade e de progresso, que, por sua vez, estavam ligados às práticas científicas 
nacionais e internacionais da época, atrelando-os ao desenvolvimento da ciência. Sendo os Boletins representantes dessa ideologia científica, a sua produção não poderia ficar aquém, nem no que concerne à qualidade dos textos neles publicados, nem no que se refere aos seus atributos imagéticos, que deveriam estar de acordo com os parâmetros de modernidade então em voga.

Goeldi (1904, p. 488) preocupava-se também com os aspectos que ele designava como "feição externa das publicações" e "qualidade do material para impressão". Considerava as artes gráficas de grande importância para a difusão do material produzido pelas instituições de ciência, e se ressentia da impossibilidade da utilização de "imagens intercaladas no texto", pois a área de produção gráfica ainda não conseguia suprir as exigências do Museu Paraense. Por isso, as ilustrações que faziam parte do material impresso nos primeiros exemplares do Boletim eram apresentadas separadamente (Figura 6). De acordo com as palavras de Goeldi (1904, p. 488), "xylographia, zincografia e correlativas artes gráficas ainda não se estabeleceram entre nós de modo que possa corresponder às exigências de um estabelecimento scientifico como é o Museu estadoal".

Figura 6 - Exemplares de páginas das primeiras edições do Boletim do Museu Paraense de História Natural e Ethnographia, evidenciando o tratamento textual e ilustrações (Litografias de C. Wiegandt).
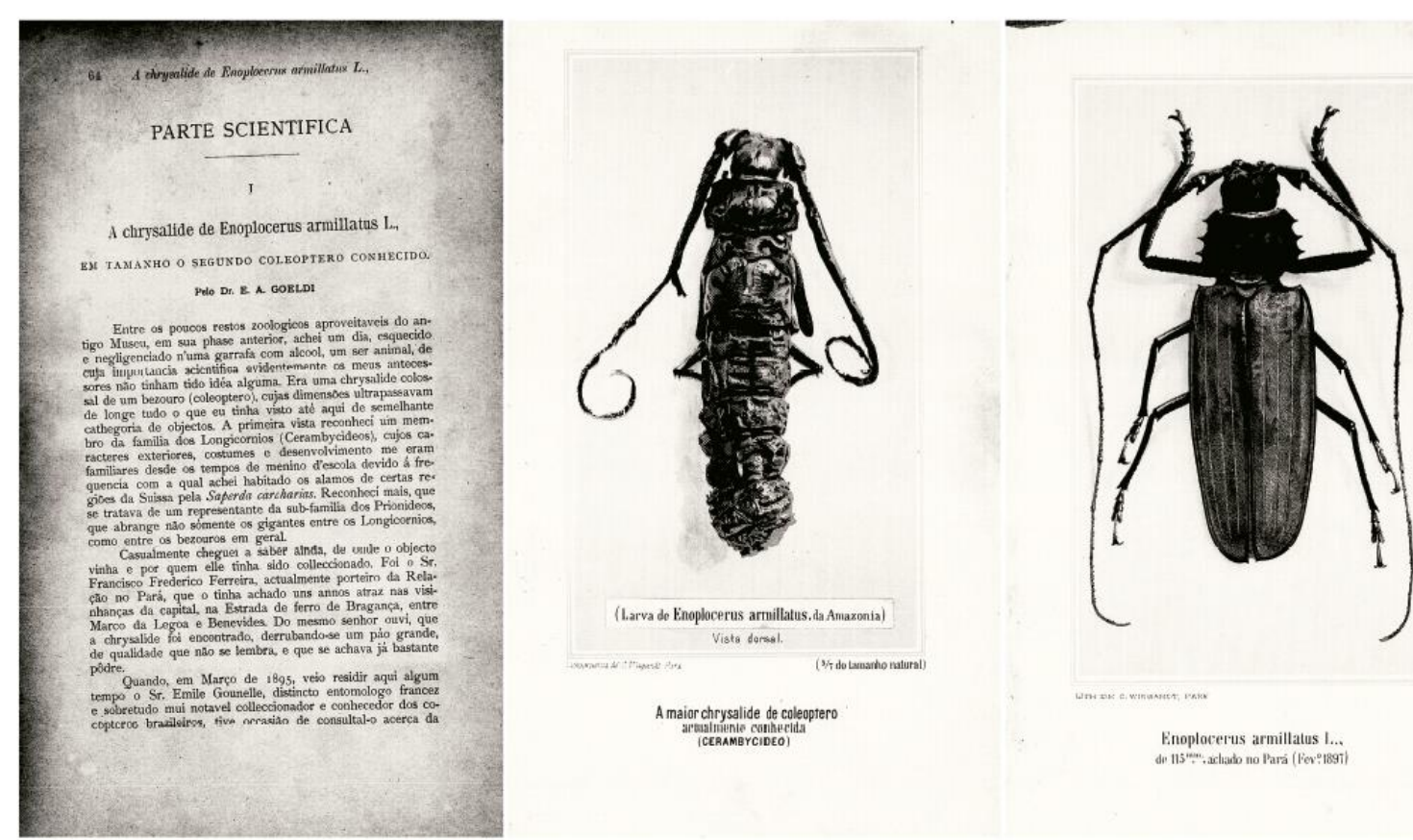

Fonte: Boletim do Museu Paraense de História Natural e Ethnographia (1897, p. 61, 63 e 64).

Do ponto de vista gráfico, portanto, verificamos que a produção se deu com o uso dos melhores recursos da época, por meio de ilustrações, sendo que algumas vezes a impressão 
ficou sob o encargo de profissionais do exterior. Em diversos períodos de seu percurso, houve preocupação de que o periódico estivesse sempre afinado com as diversas tecnologias disponíveis de cada época, ocorrendo uso desses elementos na produção, no tratamento e na publicação de imagens, por exemplo, a fim de se apoiar o conceito de modernidade na produção e na difusão da ciência.

Nas primeiras edições do Boletim, percebemos o significado que as imagens tinham para a difusão científica. A exemplo disso, em um dos textos publicados nesta época da revista, notamos a estratégia utilizada para chamar a atenção da população amazônica para o singular peixe Lepidosiren paradoxa, popularmente conhecido como piramboia (do tupi, pirá = peixe; $m b o \hat{a} a=$ cobra $)($ GOELDI, 1897). A estampa do exemplar, publicada no Boletim de 1896, também teve circulação avulsa, na forma de um folheto impresso, contendo a imagem do espécime (Figura 7). Apesar de contribuir de maneira significativa para a popularização da ciência, havia o interesse evidente em despertar o olhar do público para "reconhecer e redescobrir a Lepidosiren tão desejada por todos os Museus de História Natural” (BOLETIM DO MUSEU PARAENSE DE HISTÓRIA NATURAL E ETHNOGRAPHIA, 1896, p. 439).

Figura 7 - Cópia da estampa original da Piramboia, em litogravura, produzida pelo naturalista Johannes von Natterer.

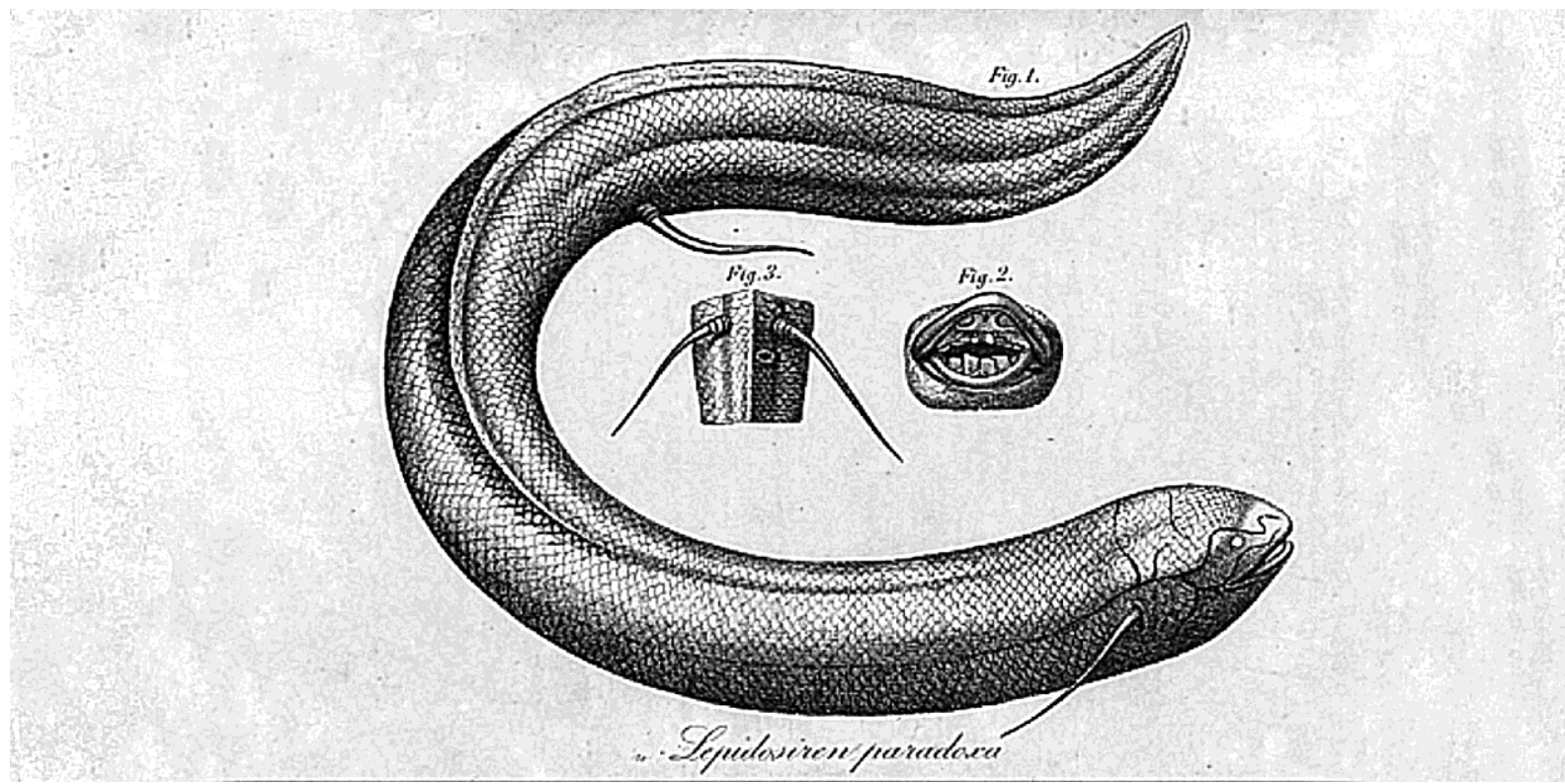

Fonte: Boletim do Museu Paraense de História Natural e Ethnographia (1896, p. 243).

Outro exemplo a ser destacado dá uma noção do que significava, para os cientistas, o uso de imagens como recurso a auxiliar na interpretação da região e, sobretudo, para fins científicos. Emílio Goeldi (1896a, p. 402) declarou: “A extraordinaria belleza que emprestam 
a estas regiões as Podostemaceas em flor, sobretudo a phenomenal Mourera fluviatilis, intitulada 'uapé das cahoeiras' pela população indígena”, acrescentando que esta espécie merecia a atenção de um artista-pintor, digna de um “pincel de Raphael” (Figura 8). As estampas produzidas a partir desse espécime seriam muito úteis aos cientistas, pois não existia, em publicação alguma, uma ilustração que desse adequadamente uma ideia mais clara a respeito da aparência, ou do "hábito fisionômico", desta planta (GOELDI, 1896a, p. 402).

Figura 8 - Estampa de Mourera fluviatilis (uapé das cachoeiras), cópia da litografia de C. Wiegandt, Pará.

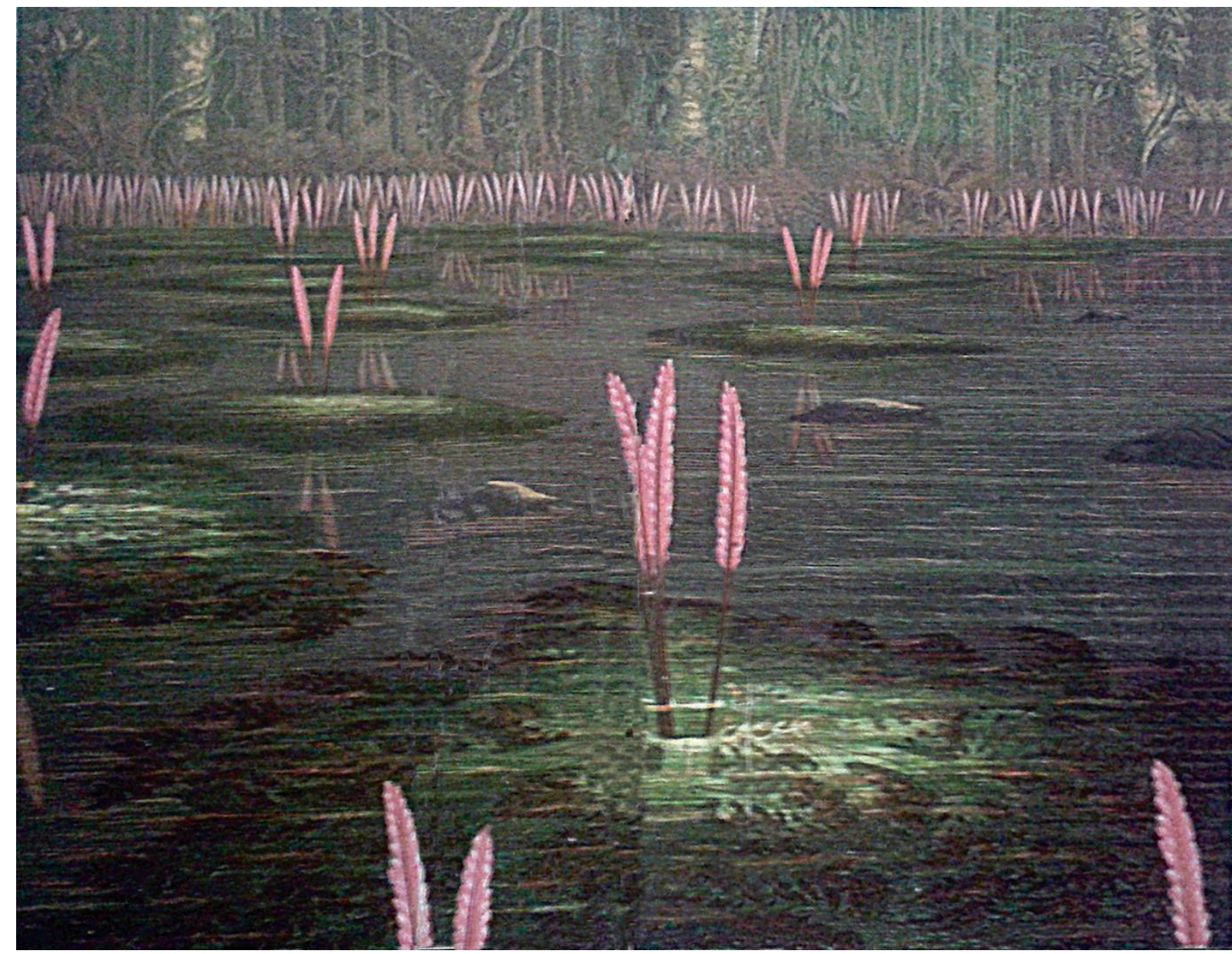

Fonte: Goeldi (1896a, p. 402).

No ano de 1897, foram publicados os números 1 e 2 do segundo volume do periódico, "com a paginação sucessiva empregada para cada número" (BOLETIM DO MUSEU PARAENSE DE HISTÓRIA NATURAL E ETHNOGRAPHIA, 1900, p. 42), totalizando 256 páginas, com 11 estampas, sendo oito produzidas no Pará e três na Alemanha. A tiragem passou de 1.000 exemplares, no primeiro volume, para 1.500, neste segundo, em função de o Boletim já registrar circulação internacional e também para diversas regiões do Brasil, entre 
“Escolas Superiores, Magistrados, Scientistas e Literatos" (GOELDI, 1900, p. 43). Nos anos seguintes, o prestígio do Boletim perante a comunidade científica aumentou, havendo crescimento de solicitação de exemplares.

Em 1902, foram publicados os números 3 e 4 do volume 3 do periódico, que totalizavam 361 páginas, com 15 ilustrações. De conteúdo variado, a publicação destes números tardou a sair, gerando um intervalo de aproximadamente três anos, justificado pela mudança de impressão do material, que passou da "Typographia de Alfredo Silva \& Cia", para ser realizada pelo Instituto Lauro Sodré, sendo necessária adequação de várias ordens, "tanto de aquisição de material como papel e tipos até de pessoal adaptado às necessidades de produção" (GOELDI, 1904, p. 488). A impressão realizada pelo instituto também trouxe grandes vantagens financeiras, pois seu custo foi reduzido pela metade.

Outra importante alteração ocorrida na edição de 1902 foi a mudança do título da publicação, com o acréscimo do nome "Museu Goeldi", entre parênteses, em decorrência da alteração do nome da instituição, que, a partir de 1900, por decreto do então governador do estado, Paes de Carvalho, passou a ser denominada oficialmente de Museu Goeldi, no lugar de Museu Paraense.

A edição de 1904 registrou dois momentos dignos de destaque: o Boletim deixou de ser integralmente publicado pelo Instituto Lauro Sodré, sendo que parte do número foi produzida pelo Estabelecimento Graphico de C. Wiegandt; também nesta edição, foi publicado importante artigo de autoria de Emílio Goeldi sobre os mosquitos do Pará, com enfoque sanitário. Goeldi procurou identificar as principais espécies de mosquitos da Amazônia, bem como seu ciclo reprodutivo e biológico, considerando de suma importância a divulgação dos meios de combate aos mosquitos e da profilaxia e do controle da febre amarela, da malária e da filariose, doenças que preocupavam o poder público. A questão levantada por este artigo incentivou as autoridades locais a convidarem Oswaldo Cruz para promover ações de profilaxia contra as moléstias que devastavam a região.

Em 1907, com o retorno de Emílio Goeldi à Suíça, o Boletim passou à responsabilidade do Sr. Jacques Huber, botânico de nacionalidade igualmente suíça e que, com a saída de Goeldi, assumiu a direção da instituição. Na capa do periódico, outra particularidade deste ano, o nome Goeldi passa a ser mais destacado: onde se lia "Boletim do Museu Paraense...", passou a ler-se "Boletim do Museu Goeldi...", ficando o termo "Museu Paraense" entre parênteses a partir deste número. 
Ainda sob a responsabilidade de Huber, seriam veiculadas mais duas edições. A edição de 1910, publicada em 1913, foi produzida pela Litho-Typographia Ernesto Lohse \& Cia. Porém, as crises orçamentárias começaram a assombrar o Museu nos anos seguintes, o que se tornou fator determinante para a produção do Boletim.

Em 1914, foi publicada a última edição desta primeira fase. Nessa época, em decorrência do declínio da economia da borracha, aliado à escassez de relação comercial com a Europa, palco do primeiro grande conflito mundial, o estado do Pará e, consequentemente, o Museu atravessavam grave crise. Emilie Snethlage, diretora e única pesquisadora a permanecer na instituição, foi a responsável por esta edição, cujo material foi impresso na cidade de Burg, na Alemanha, por Auguste Hopfer.

O Boletim parou de circular e só voltou a se fazer presente 20 anos depois, em 1933, alguns anos após o major interventor federal do estado do Pará, Joaquim de Magalhães Cardoso Barata, determinar definitivamente, por meio de decreto de lei, em 1931, a mudança da nomenclatura da instituição para "Museu Paraense Emílio Goeldi".

\section{DIZERES PARA CONCLUIR}

Atuando como cientista-editor, Emílio Goeldi compreendia o papel das publicações para a difusão da ciência, sendo o Museu Paraense, "durante sua gestão, uma das instituições científicas brasileiras, talvez a principal, que mais investiu em publicações próprias" (SANJAD, 2009, p. 143). Entre elas, o periódico científico do Museu Paraense destaca-se como marco na projeção da ciência regional, estabelecendo-se como elemento indissociável da formação da dinâmica técnico-científico que penetrou no tecido socioeconômico e político da região, até os dias atuais, reproduzindo as manifestações do cenário local por meio das pesquisas realizadas, propagando ao mundo um sentido de realidade amazônica e provocando um olhar mais interessado sobre a região.

Entre idas e vindas, períodos de descontinuidades e suspensões, os Boletins do Museu Paraense Emílio Goeldi resistem. A preocupação por parte de Goeldi em associar a qualidade do material impresso à higienização, à beleza e à dinâmica de um tempo que via na elegância e no requinte o retrato do que era civilizado e moderno persiste mesmo em momentos de crise e se intensifica na fase contemporânea, com preocupações e parâmetros semelhantes, que ajudaram a criar e a fortalecer a marca dos Boletins, traduzida em qualidade e confiança na validação de seu conhecimento. Os cuidados com a produção do material - a apresentação da capa, o tratamento de imagens, a utilização adequada das ilustrações e das fotografias, a 
organização gráfica e a distribuição do material nas páginas, por exemplo - são elementos constituintes do processo de difusão do conhecimento e, como parte integrante, precisam receber atenção, pois as falhas ocasionadas podem gerar enfraquecimento de credibilidade quanto à qualidade que se pretende associar com a marca institucional.

A atuação política, econômica e social dos Boletins enquanto instrumentos de legitimidade científica, tida como subsídio para ações do Estado, também nos permite analisar o tecido social, caminhar pelas múltiplas realidades e contextos que forjaram a história da comunicação científica local, fazendo-nos perceber as conexões existentes entre as práticas humanas e o desenvolvimento do conhecimento. Nessa perspectiva, de tempo/conhecimento, os Boletins configuram-se como patrimônio da ciência local, imbuídos de um significado maior, indo além de objetos de repositório para os resultados de pesquisa. O periódico representa uma parte da história da nossa ciência. Em suas páginas, eles carregam mais do que conhecimento, mais do que história, trazendo em si um esplêndido retrato que nos mostra os caminhos que a ciência trilhou até hoje, servindo de alicerce para a consolidação de um circuito comunicativo, configurado ontem, para ler o amanhã.

\section{REFERÊNCIAS}

AGAMBEN, Giorgio. O que é o contemporâneo? E outros ensaios. Chapecó: Santa Catarina: Argos, 2009.

A PROVÍNCIA DO PARÁ, Belém, ano XX, n. 5.593, 15 mar. 1895a. p. 2.

BENCHIMOL, A. Resgate e ressignificação da pesquisa no Museu Paraense Emílio Goeldi: presença e permanência de cientistas estrangeiros (1894-1914) na produção científica de autores atuais (1991-2010). 2015. 178 f. Tese (Doutorado em Ciência da Informação) - Instituto Brasileiro de Informação em Ciência e Tecnologia/Universidade Federal do Rio de Janeiro, Rio de Janeiro, 2015.

BOLETIM DO MUSEU PARAENSE DE HISTÓRIA NATURAL E ETHNOGRAPHIA. Belém: MPEG, 1900.

BOLETIM DO MUSEU PARAENSE DE HISTÓRIA NATURAL E ETHNOGRAPHIA. Belém: MPEG, 1897. v. 1, n. 2.

BOLETIM DO MUSEU PARAENSE DE HISTÓRIA NATURAL E ETHNOGRAFIA. Belém: MPEG, 1894-1896. v. 1, fasc. 1-4, p. 1-65.

BOLETIM DO MUSEU PARAENSE DE HISTÓRIA NATURAL E ETHNOGRAPHIA. Belém: MPEG, 1896. v. 1, n. 3.

BOLETIM DO MUSEU PARAENSE DE HISTÓRIA NATURAL E ETHNOGRAPHIA. Belém: MPEG, 1894. v. 1, n. 1. 
DANTES, M. A. M. Fases da implantação da ciência no Brasil. Quipu, México, v. 5, n. 5, p. 265-275, 1988.

FAULHABER, P.; TOLEDO, P. M. Conhecimento e fronteira: história da ciência na Amazônia. Belém: Museu Paraense Emílio Goeldi, 2001.

GOELDI, E. Relatório sobre o Museu, referente ao ano 1902, apresentado ao Exmo. Sr. Secretário da Justiça, Interior e Instrução Publica, pelo Diretor do Museu. Boletim do Museu Paraense de História Natural e Ethnographia, Belém, v. 4, p. 467-510, 1904.

GOELDI, E. Relatório sobre o Museu, relativo ao ano de 1897, apresentado ao Exmo. Sr. Dr. José Paes de Carvalho, Governador do Estado do Pará, pelo Diretor do Museu Paraense. Boletim do Museu Paraense de História Natural e Ethnographia, v. 3, n. 1, p. 1-53, 1900.

GOELDI, E. Lepidosiren paradoxa. Boletim do Museu Paraense de História Natural e Ethnographia, Belém, v. 2, n. 2, p. 247-250, 1897.

GOELDI, E. A. Lancear de olhos sobre a fauna dos Reptis do Brasil. Boletim do Museu Paraense de História Natural e Ethnographia, Belém, v. 1, n. 4, p. 402-433, 1896a.

GOELDI, E. Relatório sobre o Museu, relativo ao ano de 1895, apresentado ao Exmo. Sr. Dr. Lauro Sodré, Governador do Estado do Pará, pelo Diretor do Museu Paraense. Boletim do Museu Paraense de História Natural e Ethnographia, v. 2, n. 1, p. 232, 1896 b.

GOELDI, E. Relatório apresentado pelo Director do Museu Paraense ao Sr. Dr. Lauro Sodré, Governador do Estado do Pará. Boletim do Museu Paraense de História Natural e Ethnographia, Belém, v. 1, n. 3, p. 217-239, 1895.

GOELDI, E. A. Carta-Circular. Boletim do Museu Paraense de História Natural e Ethnographia, Belém, v. 1, n. 1, p. 8-10, 1894a.

GOELDI, E. Relatório sobre o estado do Museu Paraense. Boletim do Museu Paraense de História Natural e Ethnographia, Belém, v. 1, n. 1, p. 10-20, 1894 b.

LISBOA, K. M. Spix e Martius, historiadores da natureza. História Viva, São Paulo, p. 42-47, 1 abr. 2010.

NONATO, J. M. D. A comunidade de pesquisa da região Norte: perspectivas sobre o papel da ciência na construção do desenvolvimento sustentável. 2012. Tese (Doutorado em Geociências) Universidade Estadual de Campinas, Campinas, 2012.

ONO, Elaynia Cristina Vicente. Boletins do Museu Paraense Emílio Goeldi: institucionalização e comunicação científica na Amazônia. 2018. Dissertação (Mestrado em Ciências da Comunicação) Universidade Federal do Pará, Belém, 2018.

SANJAD, N. A Coruja de Minerva: o Museu Paraense entre o Império e a República (18661907). Brasília: Instituto Brasileiro de Museus; Belém: Museu Paraense Emílio Goeldi; Rio de Janeiro: Fundação Oswaldo Cruz, 2010. 496 p.

SANJAD, N. Emílio Goeldi (1859-1917): a ventura de um naturalista entre a Europa e o Brasil. Rio de Janeiro: EMC, 2009. 232 p.

SANJAD, N. Emílio Goeldi e o Museu Paraense. In: SANJAD, N.; VELTHEM, L. H. Reencontros: Emílio Goeldi e o Museu Paraense. Belém: Museu Paraense Emílio Goeldi, 2006. p. 17-21. 
SANJAD, N. Bela Adormecida entre a vigília e o sono: uma leitura da historiografia do Museu Paraense Emílio Goeldi, 1894-2000. In: FAULHABER, P.; TOLEDO, P. M. (Org.). Conhecimento e fronteira: história da ciência na Amazônia. Belém: Museu Paraense Emílio Goeldi, 2001. p. 113-145.

SNETHLAGE, E. Introdução. Boletim do Museu Paraense (Museu Goeldi) de História Natural e Ethnographia, Belém, v. 8, p. 1-2, 1914.

VOGT, C. Ciência, comunicação e cultura científica. In: VOGT, C. (Org.). Cultura científica: desafios. São Paulo: Edusp/FAPESP, 2006. p. 19-26.

Original recebido em: 25 de maio de 2020

Aceito para publicação em: 23 de outubro de 2020

Elaynia Cristina Vicente Ono

Mestre em Ciências da Comunicação pelo programa de Pós-graduação Comunicação, Cultura e Amazônia (PPGCOM) da Universidade Federal do Pará - UFPA. Pós-graduada (Lato Sensu) em Comunicação Institucional da Amazônia, e graduada em Comunicação Social- Publicidade e Propaganda pela Universidade da Amazônia (UNAMA). Integrante do Grupo de Pesquisa em Propaganda e Publicidade - GRUPPU (UFPA/CNPq). Possui experiência profissional na área de Comunicação, com ênfase em Produção Editorial e Design Gráfico, participou como membro integrante do Núcleo Editorial do Boletim do Museu Paraense Emílio Goeldi; e na área de educação como docente do ensino infantil e do ensino superior no Curso de Design Gráfico.

\section{Guaciara Barbosa de Freitas}

Doutora em Ciências da Comunicação pela Universidade do Vale do Rio dos Sinos (Unisinos), Mestre em Comunicação e Culturas Contemporâneas pela Universidade Federal da Bahia (UFBA), Graduada em Comunicação Social - Jornalismo pela Universidade Federal do Pará (UFPA), Pós-Doutorado realizado com bolsa do Programa Nacional de Pós-Doutorado da Capes, junto ao Programa de Pós-

Graduação Comunicação, Cultura e Amazônia (UFPA), Integrante do grupo de pesquisa Ciência, Tecnologia e Arte. Na área acadêmica, possui experiência na gestão e docência de cursos de graduação em Comunicação Social, atuação como professora em cursos de graduação e Pós-Graduação na área de Comunicação e de Ensino. Pesquisou questões relativas à comunicação, cidades, cultura, audiovisual, tecnologia, movimentos sociocomunicacionais. Atualmente concentra seus estudos nas áreas de comunicação e institucionalização da ciência, metodologia da pesquisa científica, metodologias inovadoras de ensino superior, com foco em metodologias ativas, educação inclusiva, inovação e criatividade. Jornalista integrante da Assessoria de Comunicação da Universidade do Estado do Pará. 


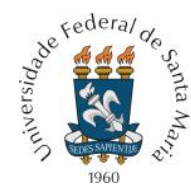

PROGRAMA DE PÓS-GRADUAÇÃO EM COMUNICAÇÃO DA UNIVERSIDADE FEDERAL DE SANTA MARIA

\section{(-) $(\Theta 0$}

Esta obra está licenciada com uma Licença

Creative Commons Atribuição-NãoComercial-CompartilhaIgual 4.0 Internacional 